$$
\begin{gathered}
\text { 이하선 종물을 주소로 내원한 } \\
\text { 외상성 외경동맥-내경정맥 루 } 1 \text { 예 }
\end{gathered}
$$

경상대학교 의과대학 이비인후과학교실, ${ }^{1}$ 진단방사선과학교실 ${ }^{2}$

김진평 ${ }^{1} \cdot$ 성병기 $^{1} \cdot$ 전시영 $^{1} \cdot$ 김재형 $^{2}$

\title{
A Case of Traumatic External Carotid Artery-Internal Jugular Vein Fistula in Parotid Region
}

\author{
Jin Pyeong Kim, MD', Byung Gi Sung, MD¹, Sea Yuong Jeon, MD and Jae Hyoung Kim, MD² \\ ${ }^{1}$ Department of Otolaryngology and ${ }^{2}$ Radiology, College of Medicine, Gyeong Sang National University, \\ Jinju, Korea
}

\begin{abstract}
-ABSTRACT -
An arteriovenous fistula represents an abnormal communication and consists of an endothelial-lined communication between an artery and vein. Its most common cause is trauma. Superficial temporal artery was involved most often, followed by facial artery, occipital artery. But external carotid artery is rare. Frequent presenting symptom is pulsating mass, pulsating tinnitus, thrill and so on. The symptoms were related to fistula site and venous drainage. Confirmative diagnosis was angiography and treatment was surgery or interventional radiology. Excision of the fistula has been the preferred method for surgical management of these lesion however, this is not always possible because the fistula may be surgically inaccessible and excessive blood loss causing by high blood flow. Recently, with advent of transcatheter interventional techniques and new embolic agents, embolization has increased popular. We experienced that a case of infraauricular pulsating mass and tinnitus due to external carotid artery-internal jugular vein fistula was obliterated by embolization of interventional radiology. (J Clinical Otolaryngol 2003;14:118-121)
\end{abstract}

KEY WORDS : Arteriovenous fistula $\cdot$ Embolization.

\section{서 론}

동정맥 누공이란 동맥과 정맥간의 비정상적인 교통을 일컫는 말로서, 동정맥 사이에 모세혈관 없이 내피세포

논문접수일 : 2002년 9월 20일 심사완료일 : 2003년 2월 19일 교신저자 : 김진평, 660- 751 경남 진주시 칠암동 90번지 경상대학교 의과대학 이비인후과학교실 전화 : (055) 750- 8175. 전송 :(055) 759- 0613 E- mail : jinpyeong@gshp.gsnu.ac.kr
로 연결되며, 하나 혹은 여러개의 입구로 연결될 수 있 고 복잡한 혈관구조를 형성할 수 있다. 동정맥 누공의 가장 흔한 원인으로는 외상으로서 주로 관자놀이, 목, 겨드랑이, 서혜부 등에 잘 발생하는 것으로 되어 있고, 주증상은 발생 부위에 따라 다양하게 나타날 수 있다. ${ }^{1)}$ Richard 등 ${ }^{2}$ 은 외상성 안면 동정맥 누공의 가장 흔한 영양동맥이 천측두 동맥, 안면동맥, 외경동맥 순이라 보 고하였다. 진단에 있어 가장 도움이 되는 것은 혈관조영 술이며, 혈관조영술에 의한 동맥색전술이 최근 치료로 각광받고 있다. 저자들은 다발성 자상에 의한 외상 후 

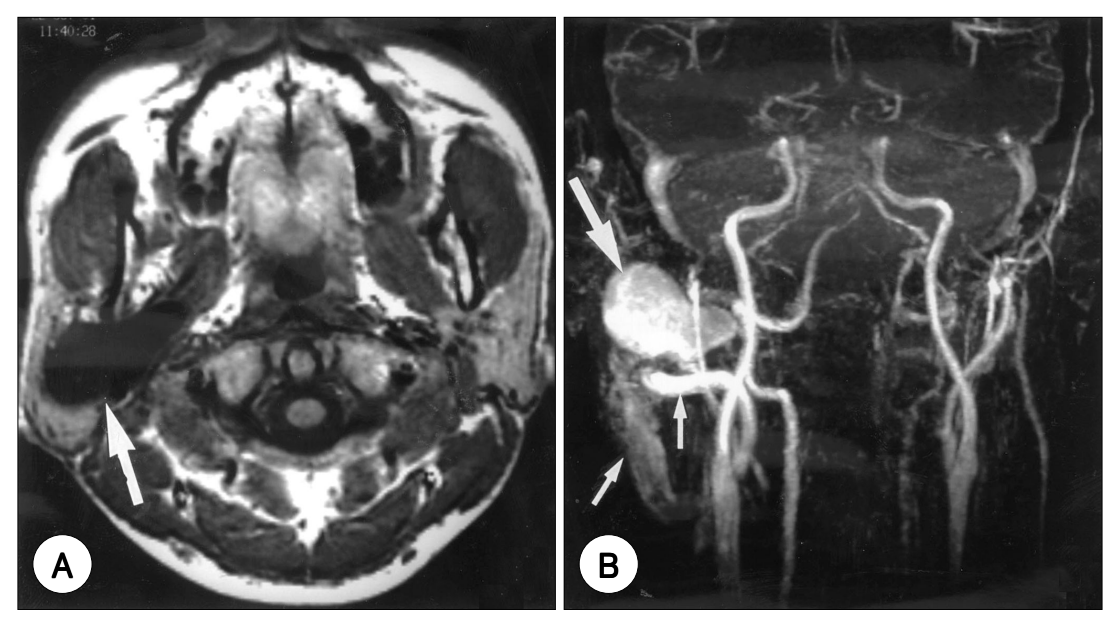

Fig. 1. A : T1-weighted image shows a large aneurysmal sac in right deep parotid area (arrow). B : MR angiogram shows the same aneurysmal sac (thick arrow), an enlarged external carotid arterial branch ( Rt. small arrow) and an enlarged draining vein ( Lt. small arrow).

약 16 개월 뒤에 발생한 이하선 종물과 박동성 이명, 진 전(thrill) 을 주소로 내원한 31세 남자 환자에서 혈관조 영술을 이용하여 외경동맥- 내경정맥 루를 확진한 후, 경 피적 동정맥 색전술로 외상성 외경동맥- 내경정맥의 누 공폐쇄를 치료를 경험한 바 있어 문헌과 함께 보고하는 바이다.

\section{증 례}

31세 남자 환자로 4개월 전부터 시작된 우측 이하선 부위 종물과 박동성 이명을 주소로 내원하였다. 과거력 상 내원 16 개월 전, 다발성 자상으로 종격동 기흉, 신장 열상으로 치료받았다. 당시 경부에도 $1 \sim 3 \mathrm{~cm}$ 크기의 다발성 자상을 입었고, 피하 기종과 인두 주위강에 종창 은 있었으나 호흡곤란과 이하선 종창은 없었다. 신체적 검사상 우측 이하선 부위에 $4 \mathrm{~cm}$ 크기의 무통성 연성 종물이 만져졌고 열감은 없었으며, 촉진시 박동성 진전이 느껴졌으며, 청진시 잡음(bruit)이 들렸다, 고막은 정상 소견이었으며, 순음 청력검사, 임피던스(Impedance) 청 력검사는 양측 모두 정상이었다. 자기공명 영상검사상 우 측 심부 이하선 부위에 $4 \times 3 \times 2.5 \mathrm{~cm}$ 크기의 낭성 종 물이 보였고, 자기공명 혈관조영술(MR- A ngiography) 상 영양 동맥은 우측 외경동맥의 분지였으며, 배출 정맥 은 내경정맥과 연결되어 있었다(Fig. 1). 경동맥 혈관조 영술상에서는 우측 총경동맥이 내경동맥과 외경동맥으로
분지되고 외경동맥 자체가 영양동맥이 되는 것으로 관찰 되었다. 동맥 색전술로 외경동맥을 Platinum coil 2개로 차단하였으나, 다른 작은 영양 동맥이 있어 동정맥 누공 낭이 희미하게 보였다. 다른 도관을 내경 정맥으로 넣고 30 개의 Platinum coils을 동정맥 누공에 가득 채워 넣 어 폐쇄하였다. 동맥 혈관 조영술상 누공낭과 배출정맥 은 더 이상 보이지 않았다FFig. 2). 이후 환자는 박동성 이하선 종물은 촉진되지 않았고, 진전이나 잡음도 없었 다. 술 후 10 개월 현재 경과 관찰 중 최대 개구시 약간 통증을 호소하는 것 이외에는 특이 소견은 없었다.

\section{고 찰}

이하선 종물은 이비인후과 영역에서 흔히 볼 수 있는 타각적 증상이며, 그 원인으로는 이하선염, 이하선 종양, 낭종 등이 흔하며, 외상에 의한 동정맥 누공의 원인으로 는 흔하지 않다. 동정맥 누공이라 함은, 동맥과 정맥간 의 비정상적인 교통을 일컫는 말로서, 동정맥 사이에 모 세혈관 없이 내피세포로 연결되며 하나 혹은 여러개의 입구로 연결될 수 있고 복잡한 혈관구조를 형성한다. ${ }^{2)}$ 주증상은 발생하는 부위에 따라 증상이 다양하게 나타 나며, 안와 혹은 안와 주위에 생기면 시력 감퇴, 안구통 등이 생길 수 있으며, 경동맥- 해면동정맥 루는 동안신 경, 활차신경, 삼차신경 및 외선신경 등의 뇌신경 장애 를 일으키며 안구로부터 정맥 환류를 일으켜 안구가 돌 


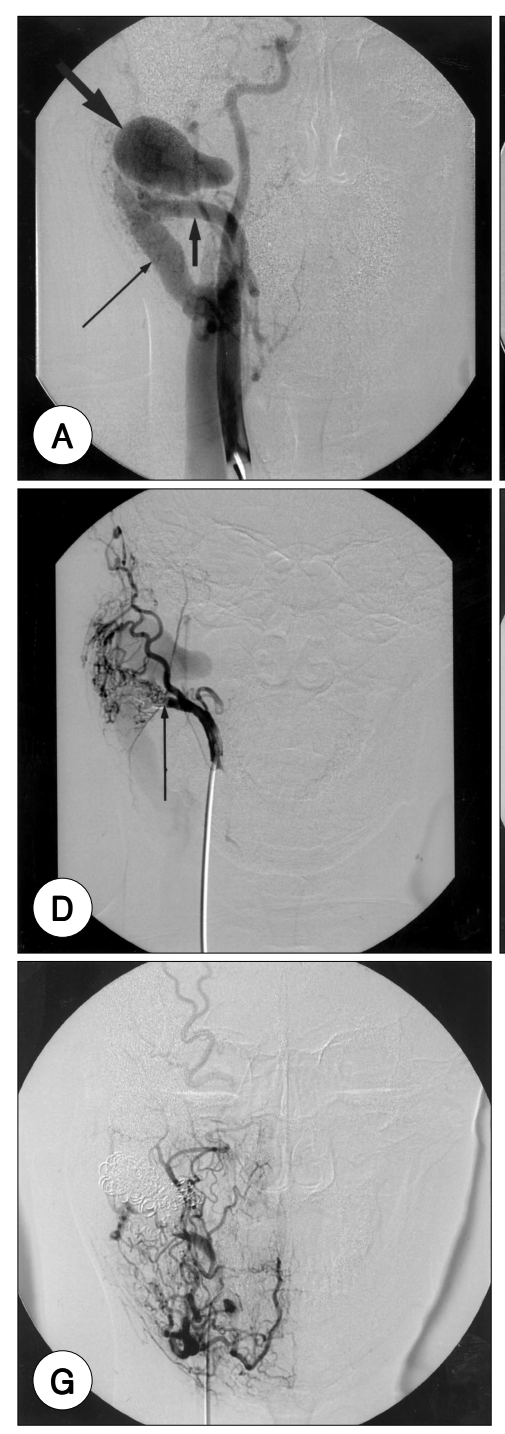

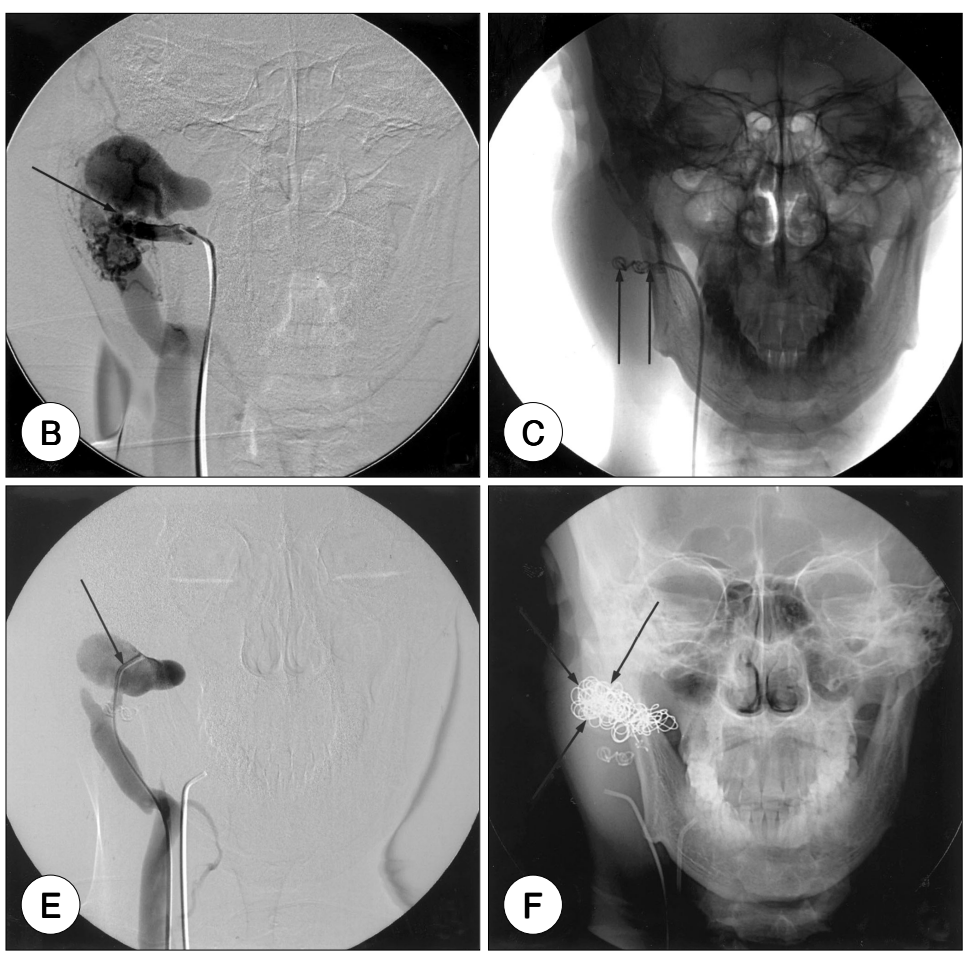

Fig. 2. A : Anterior-posterior view of right common carotid angiogram shows the same vascuar configuration as in Fig.l B aneurysmal sac (thick arrow) and enlarged draining vein (thin arrow). B : Selective angiogram of the feeding artery arrow shows small, but high-flow venous out flow, which continues to large draining veins. C : Two platinum coils ( arrows) were embolized in the feeding artery. D : Right external carotid artery angiogram after coil embolization shows complete occlusion of the feeding artery (arrow), but faint visualization of the aneurysmal sac and draining vein, suggesting the presence of another minor feeding arteries. E : Another catheter (arrow) was inserted into the aneurysmal sac via venous route. Aneurysm sac angiogram shows well visualization of an aneurysmal and a single draining vein. F : Thirty platinum micro-coils (arrows) were embolized into the aneurysmal sac through the venous catheter to obliterate the aneurysm. $G$ : Right external carotid artery angiogram after coils embolization via venous route shows no opacification of the aneurysm and draining vein.
출되고 박동성 출혈을 일으킬 수 있으며 두개내 잡음의 원인이 된다. ${ }^{2)}$ 본 증례에서는 이하선 부위에 발생하여 점진적으로 크기가 증가하는 종물과 박동성 이명, 청진 시 잡음이 있었다. 이 경우의 박동성 이명은 빈도, 강도, 그리고, 기간에 이어 다양한 소리로 감지된다. 이것의 독특한 특징은 환자의 맥박과 일치하는 리듬성을 갖고 있으며, 주로 주관적으로 호소하나, 객관적으로 나타나 기도 한다. 진전은 Valsava법에 의해 악화되며, 손가락 끝으로 가장 잘 느낄 수 있으며, 너무 심하게 누르면 혈
류 역학적 변동을 일으키고, 폐쇄가 되기도 한다. 청진 상으로는 잡음을 들을 수 있다. ${ }^{2)}$ 감별해야 할 질환으로 정맥성 잡음(venous hum), 혈관성 종양(vascular tumor), 동정맥 기형(arterio- venous malformation) 등 이다. ${ }^{3)}$ 진단을 위해서는 외상 등의 환자의 병력과 신체 적 검사 등에 의해 의심하며, 전산화 단층 촬영에 의해 진단하고, 확진은 혈관조영술로 할 수 있으며, Doppler 초음파에 의해서도 혈류의 흐름을 아는데 도움을 받을 수 있다. 본 증례에서는 비 침습적이고 주위조직과의 상 
관관계를 알기위하여 자기공명 혈관 조영술을 먼저 시 행하였고, 영양동맥과 배출정맥을 알기 위하여 경동맥 혈관조영술을 시행하였다. 신체적 검사와 자기공명영상 검사로 종물이 있음을 확인하고, 경동맥 혈관조영술로 외경동맥과 내경동맥에 누공이 있음을 확진하였다. 이 질 환의 치료에는 보전적 치료, 수술적 방법 및 중재적 방 사선학적 치료 방법이 시행되고 있다. 누공의 수술적 제 거가 더 선호되지만, 접근이 어렵거나 높은 혈류량에 의 한 대량 출혈의 원인 등으로 인하여 항상 절제가 가능 하지는 않다. ${ }^{4)}$ 수술적 치료에는 경동맥결찰술, 동맥류 제거술, 혈관 문합술 등이 있으며, 수술로 인한 사망률 은 18 24\% 로 비교적 높게 보고되고 있다. ${ }^{5) 6)}$ 단순 영 양 동맥의 결찰은 다양한 측부 순환으로 일시적 조절밖 에는 되지 않는다. 중재적 치료법은 수술을 하지 않고 혈 관조영술을 시행하면서 gel foam, silastic, metal glass, plastic pellets, autologous clot, 지방, 근육 혹은 polyvinyl alcohol 등을 사용하여 동맥류를 폐쇄할 수 있는 방법으로 $^{78)}$ 장점으로는 사망률이 거의 없고 합병증의 위험도가 낮으며, 수술로 접근할 수 없는 부위를 쉽게 접근 할 수 있고, 수기가 실패하거나 누공이 재발하여도 쉽게 반복 할 수 있다는 점이다. 색전술의 재료는 흡수성 (일시적 폐쇄) 과 비흡수성( 영구적 폐쇄) 으로 크게 분류 되며, 비흡수성 재료에 Particulate agents, Ingectable (fluid) embolic agent, sclerosing agents, Nonparticulate agent 등으로 구분할 수 있다. Platinum(Nonparticulate agent- 영구적 폐쇄) coil은 catheter tip 뒤 로 위치시키기가 힘들고, 일단 한번 사출하고 나면 회수 가 불가능하고, 효과적인 폐쇄를 위해서는 적어도 하나 이상의 coil이 필요하다는 단점이 있지만, 이용도(availability), 방사선 불투과성, 혈전성, 생물학적 적합성, 미 세도관으로 운반 가능한 것이 장점으로 보고되고 있다. ${ }^{9}$ 또 이것은 최근에 많이 사용하는 분리 풍선이 가지고 있 는 파열 위험이 없고, 부드럽고 휘기 쉬워 누공에 덜 외 상적이여서 저자들은 본 환자의 치료 재료로 선택하였 다. 코일에 의한 색전술시 합병증으로는 자기공명상 촬 영시 자기장에 영향을 주는 인공물로 작용할 수 있고, 감염 등이 생길 수 있다. ${ }^{10)}$ 따라서 감염을 줄이기 위해 서는 코일 유치 전후에 항생제 등의 투여가 필요하다. 본 증례에서는 누공의 위치가 해부학적으로 접근 가능한
부위였으나, 안면신경 손상에 의한 안면신경 마비와 경 동맥으로 부터 직접 분화 발생되어 대량 출혈의 위험성 때문에 접근이 용이하지 않았으며, 측부순환이 있어 단 순 결찰로는 해결할 수 없었기 때문에 중재적 방사선학 적 치료법을 선택하였다. 중재적 방사선학적 치료법을 시행한 후 절제술을 시행하지 않은 이유는 저자들이 사 용한 Platinum coil은 비 자기성(non- magnetic)으로 자기공명영상 촬영시 전혀 문제가 되지 않고, 또 종물이 크고, 깊은 심부까지 있어 수술시 발생할 수 있는 안면 신경마비와 작은 측부 순환으로 인한 출혈 때문이었다.

이에 저자들은 외상 후 생긴 외경동맥- 내경정맥 루를 합병증 없이 성공적으로 치료하였기에 문헌과 함께 보고 하는 바이다.

중심 단어 : 동정맥 누공. 색전술.

\section{REFERENCES}

1) Shin CS, Kim KW, Park CW, Ahn KS. Posttraumatic carotid-cavernous fistula causing severe pulsating tinnitus. Korean J Otolarygol 1994;37:1075-81.

2) Holt GR, Holt JE, Cortez EA, Thornton WR, Young WC. Traumatic facial arteriovenous malformations. Laryngoscope 1980;90 (12):2011-20.

3) Han BS, Park H, Yang HS, Kim CG. A Case of vascular tinnitus treated by transfemoral arterial embolization. Korean J Otolaryngol 1992;35:437-41.

4) Berenstein A, Scott J, Choi IS, Persky M. Percutaneous embolization of arteriovenous fistulas of the external carotid artery. AJNR Am J Neuroradiol 1986;7 (5):937-42.

5) Rich NM, Hobson RW 2nd, Collins GJ Jr. Traumatic arteriovenous fistulas and false aneurysms: a review of 558 lesions. Surgery 1975;78 (6):817-28.

6) Parkinson D, West M. Traumatic intracranial aneurysm. J Neurosurgery 1980;52:11-20.

7) Kim YD, Chung YS, Song SY, Byun YM. A Case of internal carotid artery traumatic pseudoaneurysm with epistaxis: Treated with detachable balloon occlusion (DBO) and detachable coil. Korean J Otolaryngol 1999;42:1055-9.

8) Mark MP, Chee H, Liddell RP, Steinberg GK, Panahian NP, Lane B. A mechanically detachable coil for the treatment of aneurysm and occlusion of blood vessel. AJNR Am J Neuroradiol 1994;15:821-7.

9) Yang PJ, Halbach VV, Higashida RT, Hieshima GB. Platinum wire: a new transvascular embolic agent. AJNR Am J Neuroradiol 1988;9 (3) :547-50.

10) Teitelbaum GP, Halbach VV, Larsen DW, McDougall CG, Dowd C, Higashida RT, et al. Treatment of massive posterior epistaxis by detachable coil embolization of a cavernous internal carotid artery aneurysm. Neuroradiology 1995;37 (4) :334-6. 